\title{
Advancing the Strategic Impact of Human-Centred Design
}

Published in Design Studies

DOI: https://doi.org/10.1016/j.destud.2017.06.003

(C) 2017. This manuscript version is made available under the CC-BY-NC-ND 4.0

license http://creativecommons.org/licenses/by-nc-nd/4.0/

Mieke van der Bijl-Brouwer (Corresponding Author) \& Kees Dorst

University of Technology Sydney, Faculty of Transdisciplinary Innovation \& Design Innovation

Research Centre

PO Box 123, Broadway NSW 2007, Australia, Mieke.vanderbijl-brouwer@uts.edu.au

Many organisations realise that becoming more human-centred is key to dealing with today's innovation challenges. Human-centred design (HCD) has potential to contribute to this goal. However, its current impact on strategic innovation is limited. In this paper we describe the evolution of HCD methods to date, and the challenges and opportunities of applying HCD in strategic innovation. We show that these challenges could be addressed by augmenting HCD with methods from the field of design innovation. To do this, we propose the NADI-model that links these two worlds by considering the different layers of practices and knowledge they contain, and show how the deepest level of this model can bridge human-centred design and strategic innovation.

Keywords: human-centred design, user centred design, design methods, framing, innovation 
Human-centeredness is a core quality of design. To today's product and service designers it goes without saying that products and services should meet people's needs and aspirations. Human-centred design (HCD) has gradually developed into a field of expertise of its own. This has resulted in the advent of new types of professionals, ergonomists - or human-factors experts -, usability researchers and designers, user experience specialists, as well as in a specialized academic field with dedicated conferences and academic journals.

Meanwhile, design has been gaining popularity as an approach towards tackling today's innovation challenges. This development is commonly known as design thinking, design-led innovation, or design-driven innovation (Brown, 2005; Dong, 2013; Martin, 2009; Nussbaum, 2004; Verganti, 2008). It concerns the application of design methods to innovation processes that support businesses in gaining competitive advantage, and is also gaining popularity in the social and public sector to address complex societal problems (Bason, 2010; Dorst, 2015; Manzini, 2015). Design nowadays is not just used as a process to create physical products, but increasingly also as a process that leads to the creation of any type of intervention that as Herbert Simon (1996) stated - changes existing situations into preferred ones, including services, procedures, strategies and policies. This takes design to an innovation level, and it is becoming of strategic importance to businesses and other organisations (Brown, 2005).

The design-based approach towards innovation - which we will refer to as 'design innovation' - borrows multiple elements from traditional design practices, including for example iterative design and prototyping, a systems approach, and multidisciplinary approach (for example UK Design Council, 2013). Design furthermore gains traction in the innovation field because it 'humanises' the innovation process. Gaining customer insights is seen as a key element of design innovation (Martin, 2009; Osterwalder \& Pigneur, 2010). Likewise, Hekkert and van Dijk (2011) state that understanding people, their goals and concerns, their aspirations and motives, and the world surrounding them supports innovation. The focus on human-beings in innovation has resulted in the establishment of many strategic design firms that claim to be user-, customer-, or person-centred, and an ever increasing publication of card sets, method books and tool boxes with a large variety of human-centric design methods and techniques (for example IDEO, 2015; Kumar, 2012; Luma Institute, 2012).

The fact that human-centred knowledge and practices play a key role in design innovation, creates the opportunity for the field of human-centred design to become more 
strategic. But human-centred design has been criticised for lacking the skills and knowledge that are required to operate in a strategic innovation context (Norman \& Verganti, 2014; Vassallo, 2017). Without a thoughtful consideration of how to apply HCD knowledge and practices in strategic innovation, there is a risk that its potential will not be realised. A successful adoption of HCD in innovation requires a careful analysis: we need to step back and critically identify what HCD could offer, and what not. For this purpose we will start this paper with an analysis of the past evolution and current developments in HCD methods. We will then show how human-centred design can move towards strategic human-centred innovation.

\section{THE EVOLUTION OF HUMAN-CENTRED DESIGN}

Human-centred design (HCD) is a group of methods and principles aimed at supporting the design of useful, usable, pleasurable and meaningful products or services for people. The main principle of these methods is that they describe how to gain and apply knowledge about human beings and their interaction with the environment, to design products or services that meet their needs and aspirations. There is a large variety of HCD methods, each having their own specific purpose within a specific design context. In the following brief description of the development of HCD methods we will look at the knowledge that these methods generate and how they support the design activity. The evolution is illustrated in figure 1. Please note that this linear representation is not an accurate historical account, as it does not show the complexity of how methods are interrelated. Rather, this overview is a rational reconstruction or 'family tree' that is intended to show the 'history of the ideas' that underlie HCD methods, and the way they build on each other. The creation of a new branch to this tree doesn't mean the earlier work is superseded: following Kuhn's (1962) description of the progression of Science through paradigmatic shifts, the 'old' and 'new' paradigms will always co-exist.

The presented evolution builds on other taxonomies of human-centred design that investigate different ways of integrating research about human-beings in design practice, such as Altman's (1973) models of man in environmental design, Desmet \& Hekkert's categories (2009) of integrating research about emotion in the design process, Muller and Kuhn's (1993) categorisation of participatory design methods, and Sanders and Stappers' (2008) landscape of design that shows the evolution of design research into co-design. We

(C) 2017. This manuscript version is made available under the CC-BY-NC-ND 4.0 license http://creativecommons.org/licenses/by-nc-nd/4.0/ 
introduce a perspective of human-centred design that focuses on the different views of human beings that HCD methods present - including physical, cognitive, and emotional perspectives -, as well as the various working principles that explain how these views and insights contribute to design practice.

The evolution starts with the earliest reported formal methods that put human beings at the centre of the design process, which were developed after the Second World War, to increase the efficiency of industrial production by 'fitting the task to the worker', and led to the establishment of the disciplines ergonomics and human factors (IEA International Ergonomics Association, 2006). These HCD methods were used to adjust product designs to the measurable characteristics of people. The underlying working principle was introduced to the broader consumer product design field by Dreyfuss (1955) in the fifties. He explained how appropriate products could be designed for people, and spearheaded the creation of anthropometric data sets about the population. This data is still being applied widely in design and available through books and databases that are regularly updated, for example through the work of researchers such as the TU Delft ergonomics group (Daanen, Krul, \& Molenbroek, 2004). The idea is that data about the dimensions of people can help predict if solution proposals will physically match users or not. As such the method results in constraints upon the design.

These constraints indicate what people will not or can not do when using a product, but as concluded by Kanis (1998), they do not provide any insight into how products will be used. For that purpose Dreyfuss (1955) also presented the importance of user or usability evaluations, in line with the general design principle of iterative design. These evaluations have become increasingly popular from the eighties and early nineties through the application of HCD to human-computer interfaces (for example Cushman \& Rosenberg, 1991; Nielsen, 1993a). Instead of predicting the limits of use through predefined data, actual use is studied through testing prototypes with actual users, which helps prioritising which usability problems need to be solved. The focus of HCD thus shifted from an emphasis on constraints on product characteristics to a focus on the complex interaction between people and products.

These HCD methods are based on a positivistic approach as applied in engineering and science, as reflected in the term 'usability engineering' (Nielsen (1993b)). Measurable 
requirements have to guide the design process, and controlled experiments in 'usability labs' are preferred as a method for use evaluation.

It also has gradually become clear, however, that just testing products in a lab does not provide enough externally valid insights to be able to estimate actual use in situ. This was first shown by Suchman (1987) in her work on 'situated action' which stresses that every course of action depends in essential ways on its material and social circumstances. In the 1990s we saw the development of methods to inform design by data about the context of use by conducting in situ user research such as contextual inquiry (Beyer \& Holtzblatt, 1998), testing prototypes in the field, and ethnographic methods borrowed from the fields of anthropology and sociology. These methods start from the view that interactions cannot be fully defined or anticipated in the design process. In using these methods, designers acknowledge that the interactions people will have with products will likely differ from what was intended or expected during the design process. As such, the working principle of contextualised user research is to inspire designers through 'rich' data, rather than providing them with exact answers through a controlled experiment in a lab. This has been a fundamental shift in HCD.

A downside of the context-oriented research is that although the data is rich, it does not provide straightforward answers to designers. Various scholars have argued there is a 'gap' between user research and design practice (more recently by Wixon (2003) and Norman (2010)). We can identify three working principles that have been applied in HCD to develop methods to close this gap. A first principle is aimed at having designers explore and 'sketch' descriptions of users and/ or their interactions with design proposals, which are subsequently validated with real users. So rather than showing users a prototype of a solution proposal, users are asked to provide feedback on representations of the interaction between a fictional character and that solution proposal as intended by the designer. This includes methods such as scenario-based design (Rosson \& Carroll, 2002; M. van der Bijl Brouwer \& van der Voort, 2013), use cases, and personas (Cooper, 1999) and customer journey mapping.

Other methods that are aimed at closing the gap between user research and design practice are based on one of two working principles to 'merge' the world of the designer and the world of the user. On the one hand users are invited into the world of the designer through participatory design methods, based on the Scandinavian participatory design 
movement of the 1990s (Ehn \& Sjogren, 1991; Muller \& Kuhn, 1993), and on the other hand designers are invited into the world of the user through empathy stimulating techniques such as role-playing, storytelling and experience prototypes (Buchenau \& Fulton Suri, 2000; Erickson, 1996; Kouprie \& Sleeswijk Visser, 2009; Simsarian, 2003). Many hybrid forms of collaboration and scenario-based design exist between the three above mentioned working principles, as shown subtly by Sanders and Stappers (2008) in their description of the 'new landscapes of design'. For example, design anthropology approaches - in which designers and users collaborate in staging future scenarios through performance (Halse, 2008) combine scenario-based principles with merging the world of designers and end-users.

A parallel development in the HCD field is the shift in focus from physical and cognitive characteristics of users, towards focussing on emotional needs (Overbeeke \& Hekkert, 1999) and pleasurable experiences (Jordan, 1999). Three types of design research-based approaches can be distinguished within this field (Desmet \& Hekkert, 2009). The first category is large and prominent and contains the methods borrowed from the behavioural sciences aimed at measuring the effect of product characteristics on emotions, including Desmet's (2005) foundational work on measuring emotions, and the large body of knowledge on Kansei Engineering (Nagamachi, 1995), an approach that translates the measured kansei (a Japanese term for individuals' subjective impression) of users into design parameters. Like the principle of the initial physical ergonomics and usability methods these methods are positivistic, based on controlled experiments. They inform the design process by specifying product parameters. Secondly, there are emotional design research methods which are aimed at gathering more contextualised rich data such as cultural probes which are aimed at inspiring designers (Gaver, Dunne, \& Pacenti, 1999). Thirdly, as with participatory design, in the emotional design domain there are also techniques that are aimed at bringing the world of the user and the designer closer together. Well-known techniques to bring the user into the world of designers are generative tools in which users are asked to express their ideas and dreams (Sanders \& Stappers, 2012). Methods to bring the designer into the user's emotional world are for example choreographic techniques that help designers experience and design the aesthetic qualities of tangible interaction (for example Buur, Jensen, \& Djajadiningrat, 2004). 


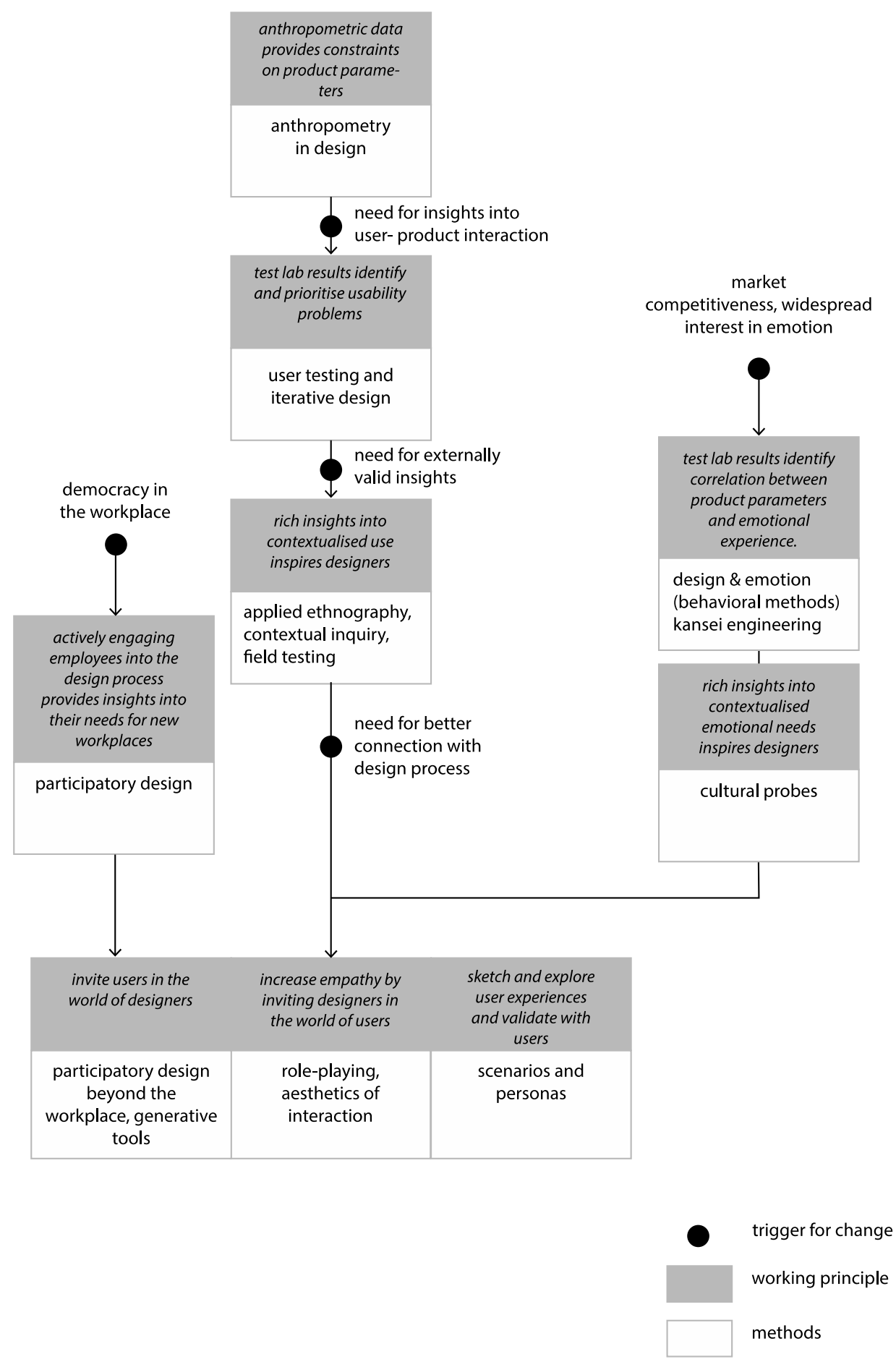

Figure 1: a rational reconstruction of the evolution of human-centred design working principles and methods 


\section{THE CURRENT OPPORTUNITIES AND CHALLENGES OF HCD}

Throughout the evolution of HCD the number of available HCD methods has been steadily increasing. Newly developed methods do often not replace older methods, but can be used simultaneously, each serving a different purpose. This has resulted in a wide variety of available HCD methods.

As we outlined in the introduction, we are now at a point where there is an opportunity for HCD to be adopted outside the traditional design field in strategic innovation processes. To support the move to this new context and ensure that HCD lives up to its potential, we need a careful analysis of what the rich field of HCD offers and still lacks. Before we do that we will first take a closer look at what strategic innovation is and how HCD could contribute.

Innovation is a broadly defined term that is used for both a process, and the outcome of that process. The innovation process can be used to create and deliver a wide variety of outputs or solution proposals, ranging from products and services, to processes, organisational methods, positions, strategies and governance (Hartley, 2005; OECD, 2005). These outputs are considered innovations when:

1. The solution proposals are novel, where the degree of novelty can be considered on a continuum ranging from incremental to radical, or continuous to discontinuous (Bessant, 2005), and/or on a relative scale from new to the organisation or firm, to new to the market, to new to the world (Bason, 2010, p41; OECD, 2005, p57)

2. They deliver value for the intended stakeholders. The innovation literature often highlights the commercial value or customer value as delivered through private sector innovation (Anderson, Narus, \& van Rossum, 2006; Osterwalder \& Pigneur, 2010), but value is also considered an essential outcome of public and social sector innovation. The latter is related to value for society and the general public and includes for example service quality and societal outcomes (for example reduced crime, educational attainment etc.), and trust, legitimacy, and confidence in the government (Kelly, Mulgan, \& Muers, 2002; Vigoda-Gadot, Shoham, Schwabsky, \& Ruvio, 2008)

3. Value can only be delivered when ideas are implemented. Innovation is therefore not just about designing products and services, but also about designing an organisation or system that is able to implement and disseminate solutions. This

(C) 2017. This manuscript version is made available under the CC-BY-NC-ND 4.0 license http://creativecommons.org/licenses/by-nc-nd/4.0/ 
includes designing business models, strategy and a 'transformation agenda' (Dorst, 2015)

It is no longer disputed that innovation is of strategic importance to organisations, because if done successfully, it contributes to the sustainability of those organisations. In the private sector innovation contributes to competitive advantage, while in the public and social sector innovation helps organisations meet their accountability requirements. Being strategic about innovation means that organisations need to invest in a process to develop novel proposals that are likely to create value for intended stakeholders. As outlined in the introduction, design has become increasingly popular as an approach to drive this innovation process. However, various scholars argue that to be able to create value, innovation is not just about meeting human needs, because customers and other stakeholders have many latent needs they cannot express. Instead, as Nussbaum (2013, p30) expressed, innovation "gets at the heart of what is truly meaningful to people". There are many indicators that in order to achieve this, innovation approaches should be aimed at gaining 'deeper' insights about users and customers, such as human values and meanings. Scholars in the design innovation field refer to these insights as 'deep customer insights' and 'deep user-centred understanding' (Bucolo, Wrigley, \& Matthews, 2012; Martin, 2009; Verganti, 2008).

There are some recent design innovation methods that implicitly or explicitly include these types of insights in an innovative design process (for example Hekkert \& van Dijk, 2011; Verganti, 2008)). However, these insights are atypical of the knowledge that has been gathered traditionally through HCD. In the evolution of HCD we could see a development from a focus on physical ergonomics, usability, context of use and user goals, to a focus on emotions and user experiences. Recently developed design innovation methods consider human needs beyond usability and emotions, and instead investigate deeper needs and aspirations. We will now explore how these methods, that have not evolved from the traditional HCD field, can augment HCD to have impact on strategic innovation. For this purpose we need to articulate clearly which methods and practices are most likely to create these strategic advantages. In particular, if the strategic application of HCD requires a deeper understanding about human needs and aspirations, then we need to be able to articulate precisely what these deep insights are, which methods can be used to gather that knowledge, and how these insights compare to knowledge gathered through other methods 
and tools. In the next section we therefore introduce a model that distinguishes different layers of depth in human needs and aspirations for use in a design and innovation process.

\section{A FOUR-LAYER MODEL OF NEEDS AND ASPIRATIONS}

To identify different types of human needs and aspirations that inform a design and innovation process, we were inspired by a multi-layer model in the field of transdisciplinary studies, developed by Jantsch (1972) and further refined by Max-Neef (2005). The model shows how disciplines each have a different purpose in a multi-level, multi-goal hierarchical innovation system. The levels build up from a practical empirical level (what exists), via a pragmatic and normative level, to a purposive or value level: the level of meaning. We compared this model to practical multi-goal, multi-level models related to products, including the 'levels of description' (product, interaction, and context) developed by Hekkert and van Dijk (2011) for use in a design and innovation process, and Sinek's (2009) 'golden circles' (what, how, why) to describe how business should communicate what they sell. Although each of these models serves a different purpose, they have in common that they show how a level that describes what exists or what could be (e.g. a product or service) is connected to a higher-level purpose of values and meanings (why something exists), via one or two levels that describe how this can be achieved.

In line with these multi-layer models we developed a four-layer model of human Needs and Aspirations for application in a Design and Innovation process (using the acronym 'NADI')(van der Bijl - Brouwer \& Dorst, 2014). The model differs from the above mentioned product-related models in that 1) it distinguishes two, rather than one level of 'whys' that each contribute to design and innovation in a different way, and 2) it does not prescribe a design or communication process, but can be used with any HCD method to identify and create deep human insights. We include the term aspiration to not just focus on direct needs, but also include longer-term hopes, desires and ambitions. We identified the levels by analysing the types of needs and aspirations that different HCD methods produce, and found that we can distinguish the following four levels of needs and aspirations: solutions, scenarios, goals, and themes (figure 2). 


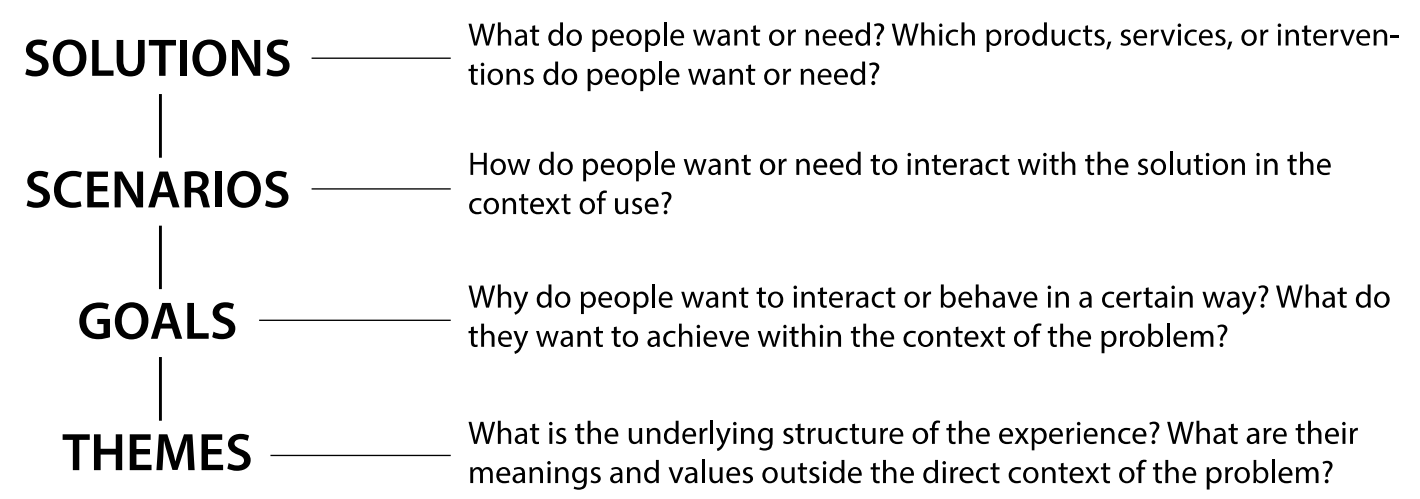

Figure 2: the NADI-model: four layers of human Needs and Aspirations for a Design and

Innovation process

On the most concrete level (top level in figure 2), the solution level, we find the insights that are related to what people need or want. The level refers to the desired characteristics of solutions such as products and services. One level deeper, the scenario level describes how people want to interact with a solution in a specific context of use. We named this level 'scenario' to highlight the influence of the context of use on interactions between people and products or services. The deepest levels of insights are the goals and themes levels, which describe why people want or need certain solutions and scenarios. The difference between goals and themes is that goals describe what people want to achieve within the context of a certain design problem, while the themes describe the underlying needs and aspirations that can be analysed independently of that context. Later in this paper we will show that it is precisely this independence of the problem context that makes themes extremely useful in a strategic design innovation process. Note that the model is fundamentally different from Maslow's hierarchy of needs (Maslow, 1943). Maslow describes needs in order of priority - lower level needs have to be satisfied before higher level needs can be addressed -, while the NADI-model describes levels connected through purpose: lower level needs contribute to higher level needs.

The term 'theme' is derived from hermeneutic phenomenology (van Manen, 1990) and based on the work of the second author of this paper on how insights into themes support the creation of frames, new approaches to problems (Dorst, 2015). He found that the explorations that designers engage in to be able to reframe problems are a subtle process of analysis that is very close to methods used in the creation of phenomenological descriptions of 'lived experience'. Just like phenomenologists, designers analyse the situation by discerning the underlying 'themes' in the life and world of the stakeholders ('what is this really about?'). For example, in their exploration of the phenomenon 'care' by nurses and 
parents in the context of children's medical treatment in hospitals, Høiseth and Keitsch (2015) described phenomenological themes such as 'feeling helpless' and 'being in an ambivalent struggle' and used these themes to inform the design of a nebulizer.

Please note that within the context of design, these themes are not static representations of direct human experiences (as in Husserl's early work, 'classic' phenomenology), but they are typically seen as part of a situated and intentional act by the prospective user (Held, 2003; Thompson, 2007; Welton, 2005). What is generally perceived by people themselves as their 'rational response' in a use situation, can be better understood through considering these deep underlying themes that inform their thinking and actions (Lakoff \& Johnson, 1999). A deep understanding of these themes can inform a reframe of the situation and the creation of radically new solutions. These solutions, based as they are on an understanding that goes deeper than what is usually expressed and thought about in the use situation, are then experienced by the users as fulfilling deep hidden needs. The fulfilling of such needs is a key driver for adoption and success (Verganti, 2016). From the perspective of strategic innovation the deeper understanding of themes is doubly important because they do not change much over time. They are the basis for longterm strategic thinking.

We will now illustrate the application of the NADI-model with a design case in which a student design team was asked to design a carrier bike: a bicycle with a box in the front, which in the Netherlands is mostly used by parents to transport their children. The team started with interviewing parents who were already using a carrier bike. One of the things the parents indicated is that they needed a detachable rain hood. In the NADI-model this refers to the solution-level. The parents furthermore indicated that they wanted the hood to be easy to set up in case of sudden weather changes during cycling. This insight explains their need on a scenario level: they describe an ideal interaction in a specific context of use. Parents also indicated that they wanted such a detachable and easy to use rain hood because they wanted to always protect their children from wind and rain while being seated in the box. This is an insight on the goal-level of the NADI-model as it describes what they want to achieve within the context of the problem.

When we look at the themes level of this case the underlying phenomenon is 'parenting'. The theme that underlies the goal 'protecting children from wind and rain' is 'protection'. This student team managed to reframe their design problem by further

(C) 2017. This manuscript version is made available under the CC-BY-NC-ND 4.0 license http://creativecommons.org/licenses/by-nc-nd/4.0/ 
investigating parents' needs. Parents had indicated that they enjoyed the carrier bike because they could see their children in front of them, and it was nice to be able to talk to them. The team furthermore found in literature about the emotional development of children that it was important for them to 'explore the world' around them. They then reframed their problem from a 'transport and protect'-problem to a problem of 'exploring the world together'. This frame can be explained through the theme of guidance as a parent. Guidance is part of 'pedagogic competence', an essential theme of parenting. Parents need to be able to help the child grow up and give shape to life (van Manen 1990). Guidance means that an interaction between the guide (parent) and the guided person (the child) takes place while the guided person interacts with the world. The interaction in the case of the carrier bike means that it should always be possible for the parents to talk to and see the child to be able to point the child at interesting elements of the environment, to give feedback on the child's observations, and to see the child's reaction. The interaction of the child with the world means that the child should always be able to look around and observe the world whilst seated in the box. The solution the student team created was a transparent hood that is open on the parent's side, so it always allows this guidance to take place, even in different weather conditions (Figure 3). This example shows how an understanding of the themes related to 'parenting' form the basis of a reframe of the problem away from being about protecting children while they are transported to being about exploring the world together, which in turn led to a more novel solution.
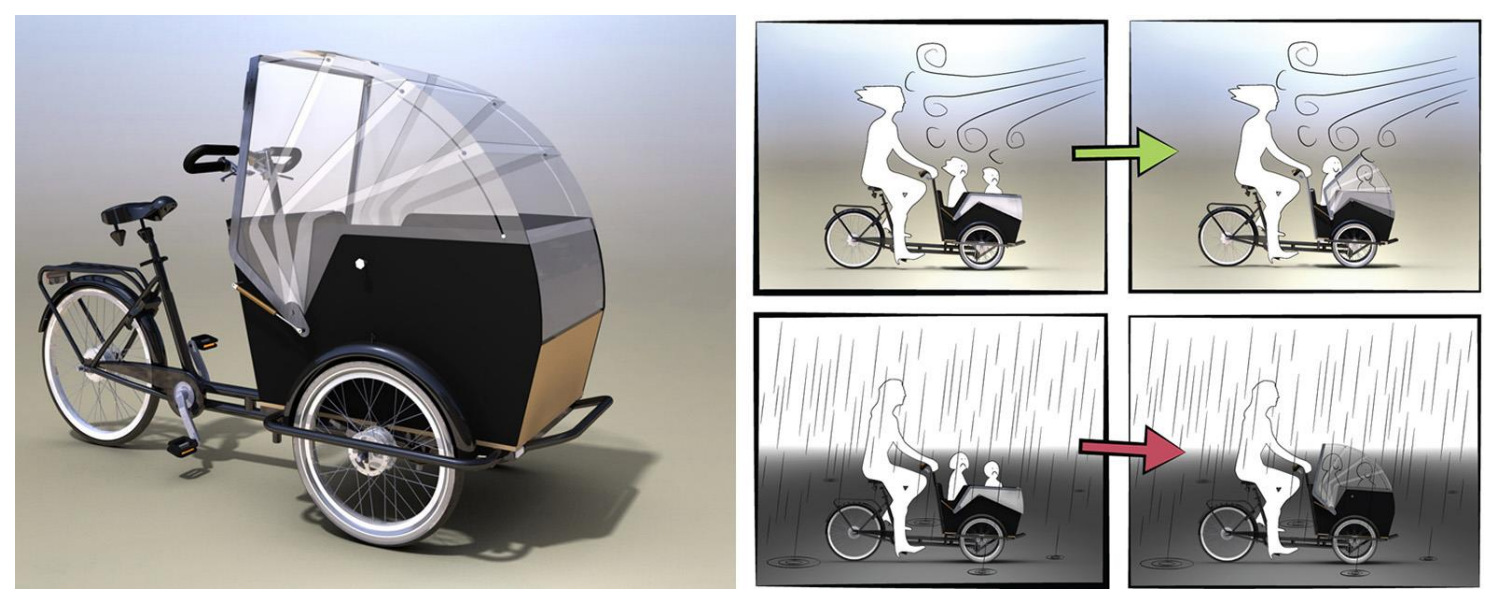

Figure 3: a carrier bike to 'explore the world together' and its envisioned scenario

Figure 4 shows the two different frames for this case study and the different levels of needs and aspirations that become relevant when looking at the design problem through the lens of these frames and the associated themes. The designed solution for the carrier

(C) 2017. This manuscript version is made available under the CC-BY-NC-ND 4.0

license http://creativecommons.org/licenses/by-nc-nd/4.0/ 
bike allows for the desired scenario to take place, and for the goal to be achieved, which in turn align with the underlying theme of guidance. This connection of the levels through purpose, provides a clear overview of why this solution proposal is likely to provide value for the intended stakeholders, in this case the targeted customers: parents.

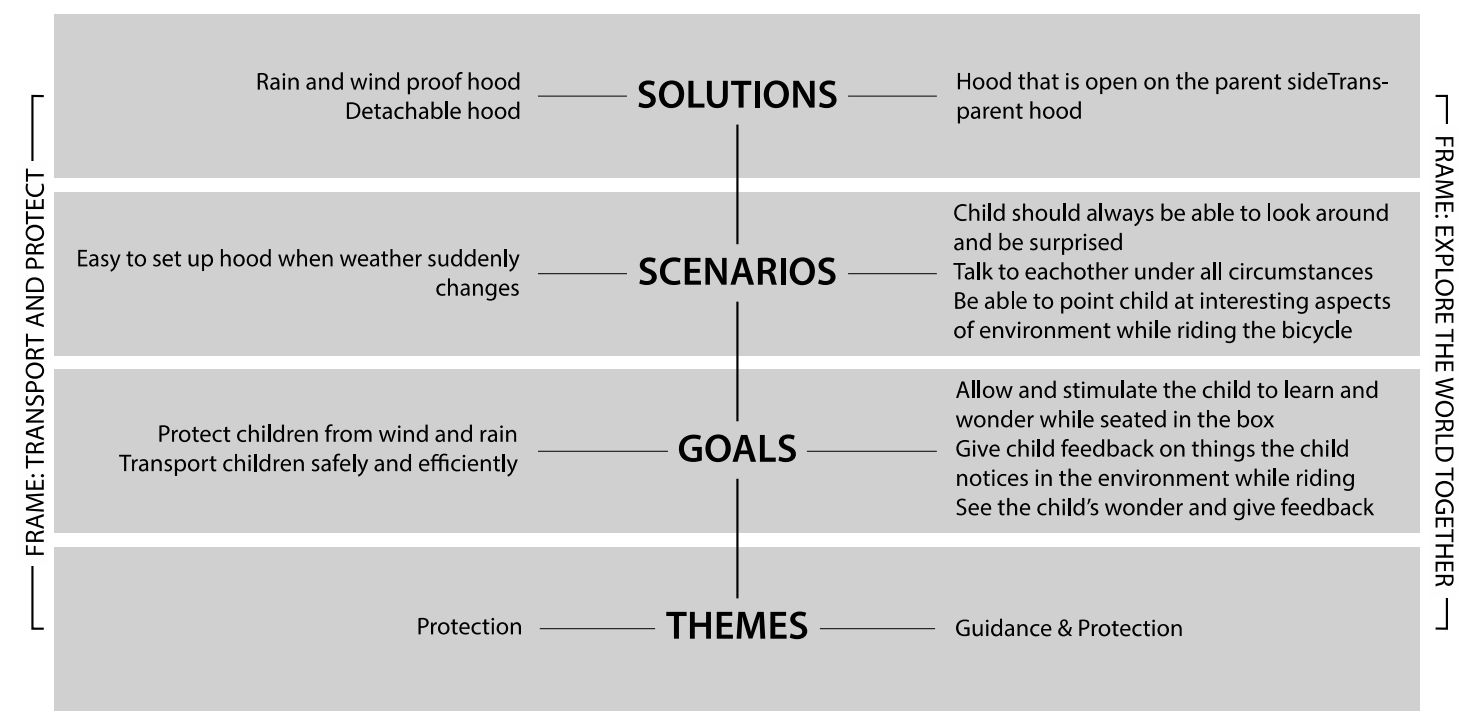

Figure 4: needs and aspirations for a carrier bike in relation to the two frames

\section{USING THE NADI-MODEL AS A LENS TO ANALYSE THE DEVELOPMENT OF HCD METHODS}

We can now compare the methods described in the evolution of HCD, as well as recently developed design innovation methods, to the four levels of needs and aspirations. Figure five shows the methods on a timeline which indicates when the method was developed. For each of the methods we analysed on which layer the methods gain knowledge related to the needs and aspirations of the target audience, using the NADImodel. 


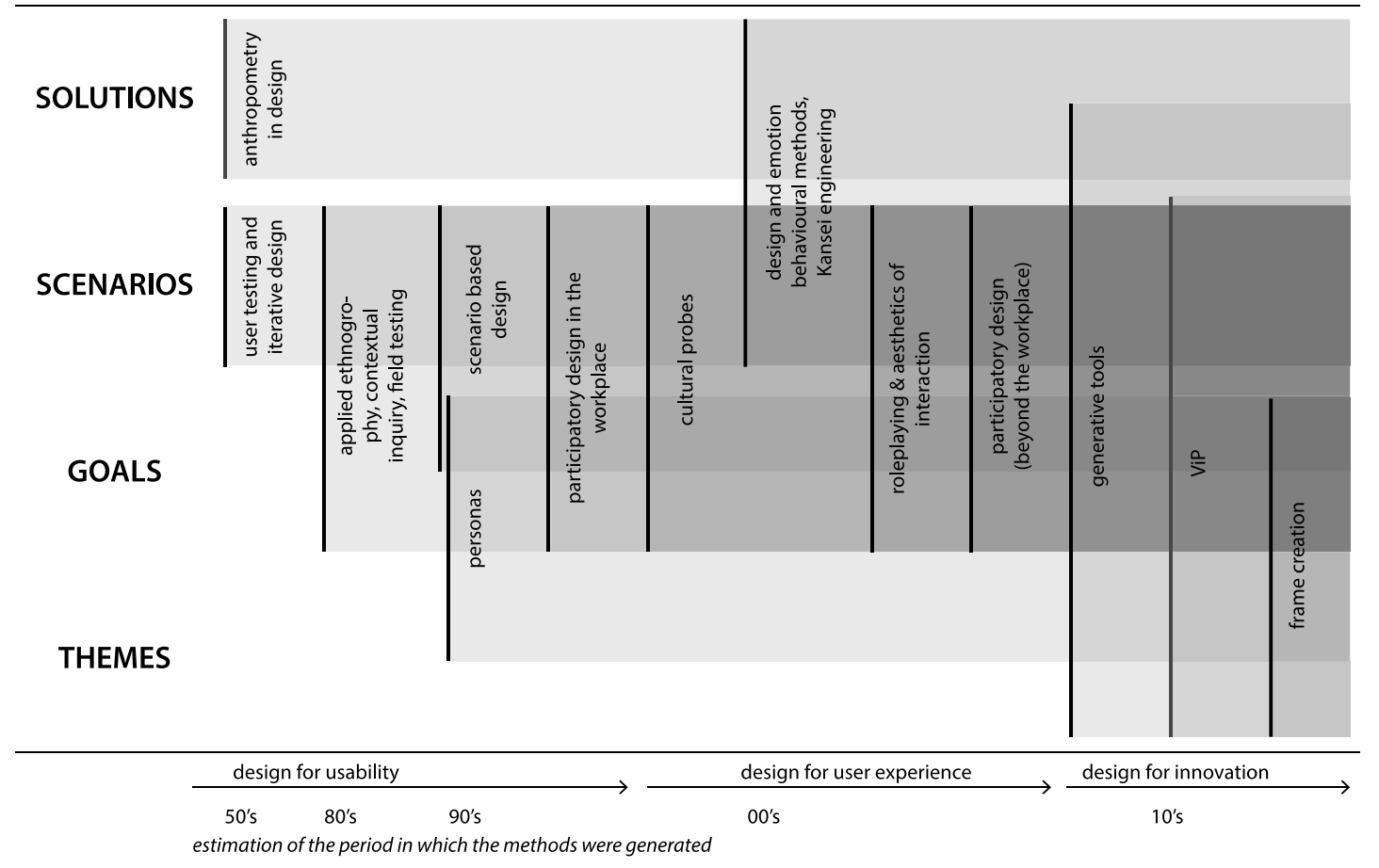

Figure 5: the layers of knowledge about needs and aspirations generated through HCD and design innovation methods with reference to the NADI-model. The figure is a visualisation of the focus area of the methods

On the solution level we find the anthropometric design method and the behavioural methods for design and emotion. These methods give insight into required product characteristics such as size, colour or aesthetic parameters in relation to physical constraints or emotional experiences. The vast majority of HCD methods provide insights on a scenario level, exploring the interaction between a product and a user. Later methods focus more on the context of use than early methods of user testing in a lab. Many methods can lead to the generation of knowledge about needs and aspirations on different levels at the same time. Scenario-based methods often produce insights about the goals that people would like to achieve within a certain scenario. For example, when interviewing someone as part of a contextual inquiry, a design researcher might find out what that person wants to achieve, depending on the questions that are being asked.

Only more recent $\mathrm{HCD}$ and design innovation methods produce knowledge that includes needs and aspirations on a theme level. The generative tools developed by Sanders and Stappers (2012) include asking people to generate and reflect on 'prototypes' (solution level). Deeper insights are then gathered from what people say about what they do or make. A laddering technique is used to move up and down an abstraction hierarchy of insights by

(C) 2017. This manuscript version is made available under the CC-BY-NC-ND 4.0 
asking why and how. This can eventually lead to the identification of human values that are independent of the problem context and are therefore related to themes. Another method that generates knowledge on the themes levels is ViP (Vision in Design) which is based on designers generating a vision or 'reason for existence' of a product, before designing the actual product (Hekkert \& van Dijk, 2011). The method is based on a model with three 'levels of description', a product level and an interaction level which clearly relate to the solution-level and scenario-level in the NADI-model, and a 'context level' which refers to the worldview of the designer and includes 'principles' and 'trends'. Principles refer to immutable laws or general patterns that can be found in human beings or nature, and can therefore be found on the theme-level in the NADI-model. The frame creation method, developed by the second author of this paper (Dorst, 2015), is a design innovation method that explicitly applies an understanding of phenomenological themes to develop frames and solution proposals for complex innovation challenges.

Concluding we can see that in the HCD-field most methods have focussed on the scenario-level and that recently design innovation methods and some HCD methods have started to move towards the deeper levels. Even though many methods are not explicitly aimed at the themes level in the NADI-model, it is relatively easy to deduce knowledge on the themes level from the higher-level insights through, for example, a laddering technique.

Just identifying deep needs and aspirations, however, will not directly lead to strategic innovation. We also need a working principle that explains how deep insights support or drive the innovation process. Although there is consensus that problem framing is an essential element in this process, it is often presented as a rather mysterious leap and attributed completely to the creative expertise of the designer. In the carrier bike case we showed how an analysis of the themes related to parenting explained the reframe of the problem and through that the innovative design of the carrier bike. It was retrospectively possible to rationalize how insights into deeper levels of human needs explained this innovative design, but we have no evidence of the actual design process that led this design team to reframe the problem. We can only attribute it to the expertise of the team. Likewise, it is easy to see how a good vision - based on an analysis of deep insights - as proposed by Hekkert and van Dijk (2011) can steer successful design, but creating this vision is not an easy task. It is a design skill that needs practice and experience to be developed. 
Available methods to support this practice are mostly aimed at increasing inspiration. For example, Sanders and Stappers $(2008$, p208) propose to organise 'inspiration events' encouraging empathy through 'immersion' in the data. However, if we want HCD to be adopted in a strategic innovation context, we will also need more concrete methods that support the innovation process, beyond relying on expert designers supported by inspirational data. The application of HCD outside the traditional design field has resulted in many novice or non-designers applying HCD. These practitioners need concrete methods that support the creation of innovative solutions. Furthermore, a clear articulation of how HCD supports strategic innovation will help in convincing strategic decision-makers of its importance.

The aforementioned frame creation method is such a concrete method for developing innovative solutions informed by deep human insights, which might form the basis for a new working principle of how HCD drives the design and innovation activity. A key feature of this method is the framing of problems based on an analysis of themes. In the next section we will explain this method and illustrate it with a case study.

\section{USING THEMES TO DRIVE STRATEGIC INNOVATION}

The frame creation method describes explicitly how the analysis of themes supports the process of framing, which in turn is an important element of innovation practices. The method was developed based on an analysis of the (re-) framing practice of expert designers (Dorst, 2015). The framing practice of designers is similar to the practice of phenomenologists in the sense that both practices include discerning underlying themes in the life world of people. For the frame creation approach, Dorst (2015) therefore proposed to use hermeneutic phenomenology (van Manen 1990) to support (re-) framing of problems. Hermeneutic phenomenology is a means to research the meaning of lived experience. We have applied frame creation in various social innovation projects, tackling a broad range of problems including crime prevention, social housing, (mental) health, and public transport (Dorst, Kaldor, Klippan, \& Watson, 2016). In this method we first use traditional HCD research methods to gather insights into stakeholder needs and aspirations at the scenario and goal levels of the NADI-model. Next, we identify themes by searching for common patterns in those insights across stakeholders. We then proceed to further analyse these themes, by investigating their meaning and relationships through analysing personal

(C) 2017. This manuscript version is made available under the CC-BY-NC-ND 4.0 license http://creativecommons.org/licenses/by-nc-nd/4.0/ 
experiences related to the theme, consulting scientific literature and philosophy on specific themes, and gathering artworks that express a theme (Rijken, 2013). The universality of themes makes it possible to analyse them independently of customers or end-users, and independent of the problem context. To move from the themes to frame the problem, we look at how the elements of the theme are dealt with in domains outside the problem context. This opens up a large body of knowledge and precedents from other fields that can lead to alternative frames. Through using metaphors, a frame can then be created which forms a bridge between problems and solutions.

We illustrate the frame creation method through a case study. The case concerned a workshop session with a group of senior public servants, to develop solutions for the problem of shortage of social housing in an Australian state. The workshop was organized as part of a training program in innovation.

The original brief for the problem drew on an historical framing of 'mutual obligation between the provider of social housing and the tenants' (see for example (Kinnear, 2002)). The aim of social housing is to provide temporary housing for tenants until they can move on to more independent types of living. The obligation of tenants is to improve their own life circumstances through, for example, education and employment, so they will be able to 'move on'. Since there are too many tenants that do not fulfil this obligation, social housing is currently reaching its full capacity.

After exploring the 'archaeology' and 'paradox' of this problem (what makes this problem so hard to solve?) - we investigated which stakeholders are - or could potentially be -involved in the sketched problem, and identified what was important to them to try and find shared themes. Common themes that were found included: self-determination and autonomy, control, belonging, trust, shelter and stability. Through a hermeneutic phenomenological exercise as explained above, some of the themes were unpacked. As an example, we summarize the analysis for control and autonomy here.

Control and autonomy are themes that apply to all the involved stakeholders. To be in control (autonomy) means having options available and knowing what the options are, and to be authorized to make the decisions. Feeling that you are in control leads to a sense of calm and self-respect. However, becoming autonomous is a learning process. It is not something that can be immediately acquired. It means that you need to step outside your comfort zone and it therefore requires confidence in one's capacities, for example, when

(C) 2017. This manuscript version is made available under the CC-BY-NC-ND 4.0

license http://creativecommons.org/licenses/by-nc-nd/4.0/ 
learning how to drive a car. You often need a trusted person (e.g. a driving instructor) to motivate you to step outside your comfort zone, and someone who provides a safety net in case you make mistakes.

The thematic analysis showed how control and autonomy are related to other themes such as trust, empowerment, safety and confidence. We then looked for metaphors that embody similar patterns of relationships to explore frames. Here we show two examples related to the theme 'control' that illustrate how the thematic analysis can change the perspective on the problem (see figure 6).

Scaffolding: this frame uses the metaphor 'scaffolding in education' as a perspective on the problem. Scaffolding consists essentially of the teacher 'controlling' those elements of the task that are initially beyond the learner's capacity, thus permitting him or her to concentrate upon and complete only those elements that are within his or her range of competence (Wood, Bruner, \& Ross, 1976). Once a student masters a task, the scaffolding can then be removed and the student will then be able to complete the task again on his or her own. This frame made participants realize that what housing providers do now is to take over control by imposing rules (mutual obligation). But they do not remove the scaffold, so it's a step back.

Reconnect/reunion: this frame is based on allowing people to find a trusted person who can support them when stepping outside their comfort zone, for example when applying for a job or enrolling in an educational program. The frame is about bringing people together and having them find a common background that connects them. This in turn supports building a social network. The social housing organisation in this frame does not provide the assistance itself, but organizes events in the community that bring people together so they can help each other.

The frames of 'reunion' and 'scaffolding' are completely different perspectives on the problem compared to the original frame of 'mutual obligation'. For a complex case like this more research and workshop sessions would be needed to explore a broader variety of themes, frames and futures. However, the case clearly shows how an analysis of the deepest level of human needs can support reframing the problem in a case of social innovation. It also shows that the independence of themes from the direct problem context opens up a large body of knowledge and precedents from other contexts that can form the basis for new frames and strategic shifts. For example the 'scaffolding' frame in this case study was

(C) 2017. This manuscript version is made available under the CC-BY-NC-ND 4.0 license http://creativecommons.org/licenses/by-nc-nd/4.0/ 
borrowed from the educational domain. Rather than reacting to what is asked for within the problem context, the method supports a strategic investigation of alternative directions.

It also takes HCD to a strategic level by integrating the design of an innovative solution, in this case a service, with implications for the transformation of the organisation. The 'reunion' frame puts social housing providers in a completely new role. Instead of providing housing and maintenance, they become event managers.

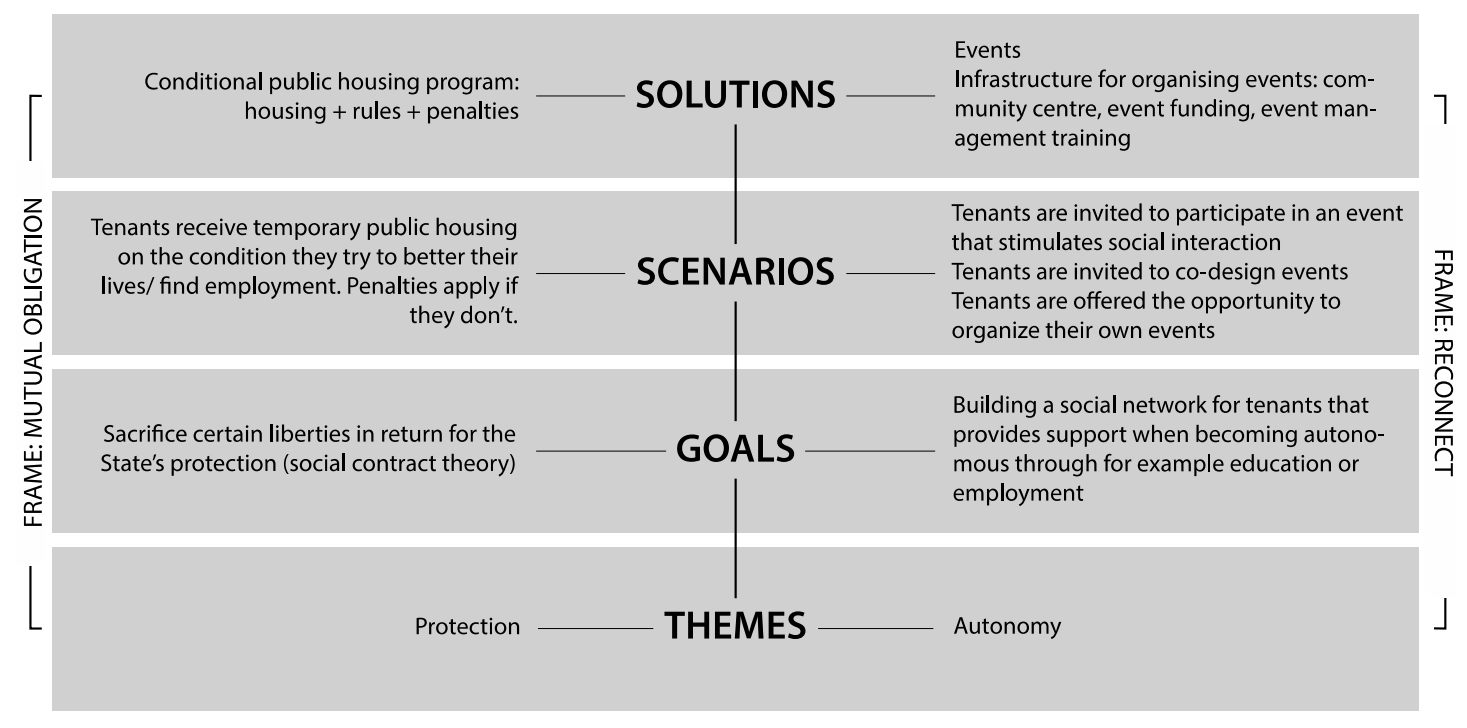

Figure 6: needs and aspirations for social housing in relation to the original frame of mutual obligation (left) and the new frame of reconnection (right)

\section{DISCUSSION}

In this paper we showed how the field of HCD is moving towards deeper levels of insights about human being's needs and aspirations. At the same time strategic design innovation is becoming more human-centric. It is now time for HCD and design innovation to join hands in generating strategic impact in the social and private sector, by learning from each other and building on each other's practices. This requires a transdisciplinary (or transpractice) approach, a coordination of the individual disciplines in which new transcending practices emerge (Jantsch, 1972). HCD offers vast experience and expertise in various ways of engaging with and understanding of human beings, while design innovation offers practical methods and tools for strategic innovation. We showed how the themes-level in the NADI-model bridges the two fields. To advance this new human-centred strategic innovation field, new methods and practices need to be developed. 
A strategic application of $\mathrm{HCD}$ requires concrete methods that explain how strategic innovation can be supported or driven by knowledge about human needs and aspirations, and in particular about themes. In comparison to more traditional HCD methods, these methods are not about responding to needs, but include a more strategic exploration of what could provide meaningful value for stakeholders. One method is the frame creation method that we presented in this paper. It is worthwhile to also investigate alternative methods for identifying and exploring themes. For example ViP (Hekkert and van Dijk 2011) offers an interesting way of looking at the theme level in the wider societal contexts through an analysis of 'principles' and 'developments'.

Furthermore, human-centred strategic innovation requires a holistic systems approach. Addressing the interests of all human beings that are part of the innovation system will contribute to positive strategic impact. This systems perspective is a core characteristic of HCD (Dul, et al., 2012). We then need to ask ourselves who should be at the centre of the strategic application of HCD. This is not just about users anymore, but about customers, service providers, citizens and other stakeholders, including people that make decisions with regard to strategy, business models, and organisational transformation. This broadens the perspective of the human beings at the centre of innovation from what Bruder et al (2012) call 'dependent stakeholder groups' such as end-users - who have little influence on the system design but have strong interest in its outcome - to dominant stakeholder groups including clients -, who have considerable power to influence design and who take the strategic decisions. This is in line with the critical analysis of the framing process by Vermaas, Dorst, and Thurgood (2015), who conclude that novel frames and related solution proposals are more likely to be adopted by clients when these frames are in line with the client's core values. The core values and themes related to dominant stakeholders will differ widely between organisations in respectively the business, social and public sector. Even though we propose that strategic innovation based on themes can be applied across these sectors, we acknowledge that the fundamental differences between core values that may be found in these sectors - e.g. a focus on competitive advantage, versus a focus on social outcomes may require specific methods and models.

Recently, Norman and Verganti (2014) published a discussion paper about the relation between human-centred design and incremental and radical innovation. Verganti (2008) defines radical innovation as the creation of new meaning, and argues that it is the core of design-driven innovation. He partnered with Norman (2014) in concluding that human- 
centred design only leads to 'hill-climbing' and that radical innovation - finding a new hill can only be achieved through meaning or technology change (which is partly tautological. If radical innovation is defined as the creation of new meaning, then suggesting that radical innovation can only be achieved through meaning change is not very helpful). If we take the old-fashioned view of HCD as a method that is all about iterative design - as originally defined by Norman himself - and thus only plays out at the scenario level, than we have to agree with Norman and Verganti. However, our description of HCD has shown that many HCD methods have started moving deeper than this scenario-level, and we have also shown how such deeper levels of understanding indeed contribute to strategic innovation. Rather than reacting to what people say they need in terms of a new product or service (solution), experience or journey (scenario), or what they want to achieve in a certain context (goals), this strategic application of HCD is about identifying the themes that describe people's deeper needs and using these themes to inform the creation of innovative strategies and solutions - new hills. This will advance the strategic impact of human-centred design.

\section{ACKNOWLEDGEMENTS}

We would like to express our gratitude to the designers and public managers who participated in the two case studies presented in this paper. We would also like to thank Dr. Clementine Thurgood for providing feedback on earlier versions of this paper.

\section{References}

Altman, I. (1973). Some perspectives on the study of man-environment phenomena. In W. F.

E. Preiser (Ed.), Environmental Design Research (Vol. 2, pp. 99-113). Stroudsburg, Pennsylvania: Dowden, Hutchinson \& Ross Inc.

Anderson, J. C., Narus, J. A., \& van Rossum, W. (2006). Customer Value Propositions in Business Markets. Harvard Business Review, 84, 90-99.

Bason, C. (2010). Leading public sector innovation. Bristol, UK: The Policy Press.

Bessant, J. (2005). Enabling Continuous and Discontinuous Innovation: Learning From the Private Sector. Public money \& management, 25, 35-42.

Beyer, H., \& Holtzblatt, K. (1998). Contextual design : defining customer-centered systems Hugh Beyer, Karen Holtzblatt: San Francisco CA : Morgan Kaufmann.

Brown, T. (2005). Strategy by Design. FAST COMPANY.

Buchenau, M., \& Fulton Suri, J. (2000). Experience Prototyping. In D. Boyarski \& W. A. Kellogg (Eds.), DIS'OO Proceedings of the 3rd conference on Designing interactive systems: processes, practices, methods, and techniques (pp. 424-433). Brooklyn, NY, USA: ACM. 
Bucolo, S., Wrigley, C., \& Matthews, J. (2012). Gaps in organizational leadership: linking strategic and operational activities through design-led propositions. Design Management Journal, 7, 18-28.

Buur, J., Jensen, M. V., \& Djajadiningrat, T. (2004). Hands-only scenarios and video action walls: novel methods for tangible user interaction design. In Proceedings of the 2004 conference on Designing interactive systems: processes, practices, methods, and techniques. Cambridge, MA, USA: ACM Press.

Cooper, A. (1999). The inmates are running the asylum: why high-tech products drive us crazy and how to restore the sanity: Indianapolis: Sams.

Cushman, W. M., \& Rosenberg, D. J. (1991). Human factors in product design: Amsterdam: Elsevier.

Daanen, H. A. M., Krul, A. J., \& Molenbroek, J. F. M. (2004). DINED anthropometic database. In: TU Delft.

Desmet, P. M. A. (2005). Measuring Emotion: Development and Application of an Instrument to Measure Emotional Responses to Products. In M. A. Blythe, K. Overbeeke, A. F. Monk \& P. C. Wright (Eds.), Funology (pp. 111-123): Springer Netherlands.

Desmet, P. M. A., \& Hekkert, P. (2009). A decade of design and emotion. International Journal of Design, 3, 1-6.

Dong, A. (2013). Design $x$ Innovation. In Proceedings of Consilience and Innovation in Design, 5th IASDR 2013 (pp. 0234-0245). Tokyo, Japan.

Dorst, K. (2015). Frame Innovation; create new thinking by design. Cambridge, Massachusetts: The MIT Press.

Dorst, K., Kaldor, L., Klippan, L., \& Watson, R. (2016). Designing for the Common Good. Amsterdam: BIS Publishers.

Dreyfuss, H. (1955). Designing for people. NYC: Simon \& Schuster.

Dul, J., Bruder, R., Buckle, P., Carayon, P., Falzon, P., Marras, W. S., Wilson, J. R., \& van der Doelen, B. (2012). A strategy for human factors/ ergonomics: developing the discipline and profession. Ergonomics, 55, 377-395.

Ehn, P., \& Sjogren, D. (1991). From system descriptions to scripts for action. In J. Greenbaum \& M. Kyng (Eds.), Design at work: cooperative design of computer design. Hillsdale, New Jersey: Lawrence Erlbaum associates.

Erickson, T. (1996). Design as Storytelling. Interactions, 3, 30-35.

Gaver, B., Dunne, T., \& Pacenti, E. (1999). Design: Cultural probes. Interactions, 6, 21-29.

Halse, J. (2008). Design Anthropology: Borderland Experiments with Participation, Performance and Situated Intervention. IT University of Copenhagen.

Hartley, J. (2005). Innovation in governance and public services: past and present. Public money \& management, 25, 27-34.

Hekkert, P., \& van Dijk, M. (2011). Vision in Design, A Guidebook for Innovators. Amsterdam: BIS Publishers.

Held, K. (2003). Husserl's phenomenological method. In The new Husserl: a critical reader (pp. 3-31). Bloomington, Indiana: Indiana University Press.

Høiseth, M., \& Keitsch, M. M. (2015). Using phenomenological hermeneutics to gain understanding of stakeholders in healthcare contexts. International Journal of Design, 9, 33-45.

IDEO. (2015). The Field Guide to Human-Centered Design. In.

IEA International Ergonomics Association. (2006). IEA 50th Anniverary booklet. In: IEA Press.

Jantsch, E. (1972). Towards interdisciplinarity and transdisciplinarity in education and innovation. In L. Apostel, G. Berger, A. Briggs \& G. Michaud (Eds.), Interdisciplinarity, problems of teaching and research in universities (pp. 97-121). Paris: OECD Publications.

(C) 2017. This manuscript version is made available under the CC-BY-NC-ND 4.0

license http://creativecommons.org/licenses/by-nc-nd/4.0/ 
Jordan, P. W. (1999). Pleasure with products: human factors for body, mind and soul. In W. S. Green \& P. W. Jordan (Eds.), Human factors in product design; current practice and future trends: Taylor \& Francis.

Kanis, H. (1998). Usage centred research for everyday product design. Applied Ergonomics, $29,75-82$.

Kelly, G., Mulgan, G., \& Muers, S. (2002). Creating Public Value: An analytical framework for public service reform. In. UK: Strategy Unit, Cabinet Office.

Kinnear, P. L. (2002). Mutual obligation a reasonable policy? In T. Eardley \& B. Bradbury (Eds.), Competing Visions: Refereed Proceedings of the National Social Policy Conference 2001 (Vol. SPRC Report 1/02, pp. 248-263). Sydney: Social Policy Research Centre, University of New South Wales.

Kouprie, M., \& Sleeswijk Visser, F. (2009). A framework for empathy in design: stepping into and out of the user's life. Journal of Engineering Design, 20, 437-448.

Kuhn, T. S. (1962). The structure of scientific revolutions. Chicago: University of Chicago Press.

Kumar, V. (2012). 101 Design Methods: a structured approach for driving innovation in your organization. Hoboken, N.J.: John Wiley \& Sons.

Lakoff, G., \& Johnson, M. (1999). Philosophy in the flesh: The embodied mind and its challenge to western thought. New York: Basic books.

Luma Institute. (2012). Innovating for people: Human-Centred Design Planning Cards. Pittsburgh, PA: LUMA Institute.

Manzini, E. (2015). Design, When Everybody Designs - An Introduction to Design for Social Innovation. Cabridge, Massachusetts: The MIT Press.

Martin, R. (2009). The design of business: why design thinking is the next competitive advantage. Boston, Massachusetts: Harvard Business School Publishing.

Maslow, A. H. (1943). A theory of human motivation. Psychological Review, 50, 370-396.

Max-Neef, M. A. (2005). Foundations of transdisciplinarity. Ecological economics, 53, 5-16.

Muller, M. J., \& Kuhn, S. (1993). Participatory design. Commun. ACM, 36, 24-28.

Nagamachi, M. (1995). Kansei engineering: a new ergonomic consumer-oriented technology for product development. International Journal of Industrial Ergonomics, 15, 3-11.

Nielsen, J. (1993a). Iterative User Interface Design. IEEE Computer, 26, 32-41.

Nielsen, J. (1993b). Usability Engineering: Academic Press, Inc.

Norman, D. A. (2010). The Research-Practice Gap: The Need for Translational Developers. Interactions, 17, 9 - 12.

Norman, D. A., \& Verganti, R. (2014). Incremental and radical innovation: design research versus technology and meaning change. Design Issues, 30, 78-96.

Nussbaum, B. (2004). The Power of Design. BusinessWeek, 86-94.

Nussbaum, B. (2013). Creative Intelligence - Harnessing the Power to Create, Connect, and Inspire. New York: HarperCollins Publishers.

OECD. (2005). Oslo Manual: Guidelines for Collecting and Interpreting Innovation Data. Luxembourg: OECD/ European Communities.

Osterwalder, A., \& Pigneur, Y. (2010). Business Model Generation, A Handbook for Visionaries, Game Changers, and Challengers. Hoboken, New Jersey: John Wiley \& Sons, Inc.

Overbeeke, C. J., \& Hekkert, P. (1999). Proceedings of the 1st International Conference on Design and Emotion. Delft: Delft University of Technology.

Rijken, G. D. (2013). The psychosocial architecture of themes. In.

Rosson, M. B., \& Carroll, J. M. (2002). Usability Engineering: scenario-based development of human-computer interaction: Morgan Kaufmann. 
Sanders, E. B.-N., \& Stappers, P. J. (2008). Co-creation and the New Landscapes of Design. CoDesign, 4, 5-18.

Sanders, E. B.-N., \& Stappers, P. J. (2012). Convivial toolbox - generative research for the front end of design. Amsterdam: BIS Publishers.

Simon, H. A. (1996). The sciences of the artificial (3rd edition ed.). Cambridge, MA: The MIT Press.

Simsarian, K. T. (2003). Take it to the Next Stage: The Roles of Role Playing in the Design Process. In Proceedings of $\mathrm{CHI}$ 2003. Ft. Lauderdale, Florida, USA.

Sinek, S. (2009). How great leaders inspire action. In: TED.com.

Suchman, L. A. (1987). Plans and situated actions: the problem of human machine communication: Cambridge University Press.

Thompson, E. (2007). Mind in life: Biology, phenomenology, and the sciences of mind. Cambridge, MA: Belknap Press.

UK Design Council. (2013). Design for Public Good. In.

van der Bijl - Brouwer, M., \& Dorst, K. (2014). How deep is deep? A four-layer model of insights into human needs for design innovation. In J. Salamanca, P. Desmet, A. Burbano, G. Ludden \& J. Maya (Eds.), Proceedings of the Colors of Care: The 9th International Conference on Design \& Emotion (pp. 280-287). Bogotá: Ediciones Uniandes.

van der Bijl - Brouwer, M., \& van der Voort, M. C. (2013). Exploring future use: scenario based design. In C. de Bont, F. E. Smulders, M. C. van der Voort, R. Schifferstein \& E. den Ouden (Eds.), Advanced design methods for successful innovation - Recent methods from design research and design consultancy in the Netherlands (pp. 5777). Delft: Design United.

van Manen, M. (1990). Researching lived experience: human science for an action sensitive pedagogy. Albany, NY: State University of New York Press.

Vassallo, S. (2017). The case against empathy. In CO.DESIGN. New York: Fast Company.

Verganti, R. (2008). Design, Meanings, and Radical Innovation: A Metamodel and Research Agenda. The journal of product innovation management, 25, 436-456.

Verganti, R. (2016). Overcrowded - desgining meaningful products in a world awash with ideas. Cambridge, MA: The MIT Press.

Vermaas, P., Dorst, K., \& Thurgood, C. (2015). Framing in design: a formal analysis and failure modes. In C. Weber, S. Husung, G. Cascini, M. Cantamessa, D. Marjanović, M. Bordegoni, S. Graziosi, F. Montagna, F. Rotini \& S. Venkataraman (Eds.), Proceedings of the 20th International Conference on Engineering Design (ICED15) (pp. 1-10). Milan, Italy: The Design Society.

Vigoda-Gadot, E., Shoham, A., Schwabsky, N., \& Ruvio, A. (2008). Publi sector innovation for Europe: a multinational eight-country exploration of citizen's perspectives. Public Administration, 86, 307-329.

Welton, D. (2005). Soft, smooth hands - Husserl's phenomenology of the lived-body. In R. Bernet, D. Welton \& G. Zavota (Eds.), Edmund Husserl: Critical assessments of leading philosophers (pp. 172-191).

Wixon, D. (2003). Evaluating usability methods, why the current literature fails the practitioner. Interactions, 10, 28 - 34.

Wood, D., Bruner, J. S., \& Ross, G. (1976). The role of tutoring in problem solving. Journal of Child Psychology and Psychiatry, 17, 89-100. 